Article

\title{
Industry Performance Appraisal Using Improved MCDM for Next Generation of Taiwan
}

\author{
Zon-Yau Lee ${ }^{1, *(\mathbb{D})}$, Mei-Tai Chu ${ }^{2}$ (D), Yu-Ting Wang ${ }^{3}$ and Kuan-Ju Chen ${ }^{4}$ (D) \\ 1 Department of International Business, Kainan University, No. 1 Kainan Road, Luzhu District, \\ Taoyuan City 33857, Taiwan \\ 2 Department of Accounting and Data Analytics, La Trobe University, Melbourne, VIC 3086, Australia; \\ m.chu@latrobe.edu.au \\ 3 Department of Business Administration, National Central University, No. 300, Zhongda Rd., \\ Zhongli District, Taoyuan City 32001, Taiwan; 104481003@cc.ncu.edu.tw \\ 4 Department of Business Administration, National Chengchi University, No. 64, Sec. 2, Zhinan Rd., \\ Wenshan District, Taipei City 11605, Taiwan; kuanjuc@nccu.edu.tw \\ * Correspondence: zylee.mt88g@mail.knu.edu.tw
}

Received: 11 May 2020; Accepted: 11 June 2020; Published: 30 June 2020

\begin{abstract}
It is critical for manufacturing sectors to improve maximum performance to foster a competitive advantage. This article aims to analyze how the manufacturing industry can promote its performance to achieve sustainable development. We embark performance evaluation on Taiwanese manufacturing sectors which have profound implications in the global manufacturing supply chain. This study collected public information and reliable data from the Industrial Technology Research Institute (ITRI) covering 12 Taiwanese manufacturing industries. Performance evaluation indicators consist of four inputs chosen from a set of six items, whereas one output is from a set of three items. The analysis from Data Envelopment Analysis (DEA) is conducted including CCR (Charnes, Cooper, \& Rhodes) efficiency, BCC (Banker et al.) efficiency, A\&P(Andersen and Petersen) efficiency, cross-efficiency and D\&G(Doyle and Green) efficiency plus the VIKOR prioritization method to evaluate the 12 manufacturing industries in Taiwan. The comprehensive analysis and comparison results of this study show the sophisticated outcomes through the analysis of DEA and VIKOR. In another objective evaluation, the efficiency of DEA proves a certain correlation between the model and the measurement of the VIKOR method. The results indicate that Taiwan's manufacturing industry is moving towards design innovation thinking towards the high value of its own brand, whereas the industries in China and South East Asia appear different. The results can provide the best practice to allow the international manufacturing industry to enjoy a resurgence after falling output and diminishing labor force.
\end{abstract}

Keywords: ITRI (Industrial Technology Research Institute); DEA (Data Envelopment Analysis); VIKOR; industry performance; multiple-criteria decision-making (MCDM); manufacturing industry

\section{Introduction}

The 2016 Global Manufacturing Competitiveness Index study highlighted the top six countries (the United States, China, Japan, Germany, South Korea, and India) in the manufacturing industry. The six countries together account for $60 \%$ of global manufacturing GDP, showing their huge influence on global manufacturing trends [1]. Particularly, Taiwan's manufacturing industry has flourished during the 1960-1980 period, and it is predominately famous for its foundry industry. Taiwan is a newly industrialized country, and its rapid economic development since the 1990s has won its title as one of The Four Dragons in Asia [2]. Although some Original Equipment Manufacturer(OEM) 
suppliers think of maintaining a competitive price advantage by moving their production bases from Taiwan to other developing countries like China and Southeast Asia [3,4], Taiwan still plays a pivotal role in the manufacturing industry.

Taiwan previously focused on efficiency-oriented manufacturing that emphasizes increasing productivity, reducing costs, and achieving economy of scale to enable Taiwan's international battle [5]. Hsueh and Chen [6] stated that in Taiwan there are a large number of Small and Medium Enterprises (SMEs) from a broad spectrum of industries have great technology adoption and innovation capacity [6]. Chen et al. [7] found that Taiwan is one of the first developing countries to open up to the international market, first targeting export markets and then shifting to direct investments from foreign multinationals [8]. Chen [9] pointed out that Taiwan is quite a valuable case for those emerging countries interested in creating a national policy and innovation strategy for transforming themselves from low-value to high-technology and high-value producers [9]. Technological innovation is seen as a tool that can stimulate economic growth and business sustainability. It is essential for policy-makers and practitioners to understand the underlying causes and mechanisms to enhance sustainability by supportive means (such as government's procurement and financial incentives), and how to evaluate industry performance to promote industrial competitiveness and technological innovation [10]. Taiwanese SME managers face the challenge of keeping their positions in the international production network, whilst many companies have relocated their manufacturing facilities to Southeast Asian countries [11]. A recent trend notices that business often outsources product manufacturing to low-cost suppliers such as China, India, or Vietnam [12]. Taiwanese investments in China have grown dramatically, focusing primarily on the labor-intensive and export-oriented manufacturing industries, such as textiles and garments, and food and beverage processing [13]. Hung et al. [14] discovered that the East Asian container ports are more efficient on average than the others, which implies that East Asian container ports are more competitive. This has been driven by the globalization of the world economy and the rise of China as the world's manufacturing center. Incentives are suggested to be given to the Foreign direct investment(FDI) with vertical integration with domestic suppliers to help local firms' gains from FDI technology transfer [15]. Emodi et al. [16] recommended government needs to set up policies to stimulate industrial $R \& D$, while supporting technology transfer from foreign partners. During 2009-2016, production factors such as rising wages in Mainland China and Southeast Asia have affected the willingness of multinational corporations to invest or move the industry out. The Taiwan government has been facing long-term industrial migration; it has actively encouraged multinational corporations to return to Taiwan [17,18]. In order to maintain market competitiveness, companies have regarded sustainable development as an important goal and initiated many sustainable development strategies [19]. For example, some addressed three aspects in terms of economy, society, and environment could become the focus of the sustainable development of enterprises [20,21]. Existing studies have shown various strategies to guarantee sustainable business, such as resource allocation, being creative, and sharing risk with suppliers [22-24]. Importantly, in addition to the transformation of the traditional manufacturing industry to achieve sustainable business operations, Taiwan's manufacturing industry could succeed in the international market in a unique direction of innovation as a useful reference point for global manufacturing sectors [25].

This study selected different models in Data Envelopment Analysis (DEA) for the performance analysis of 12 industries, first, taking the preliminary variable and using the CCR (Charnes, Cooper, \& Rhodes) model and A\&P (Andersen and Petersen) model for efficient or inefficient review. It then uses the CCR model and BCC (Charnes, Cooper, \& Rhodes) model for Pure Technical Efficiency (PTE) and Scale Efficiency (SE) to measure and assess the scale of remuneration Return to Scale (RTS) to complete a more subjective self-assessment. Next, the peer review cross-efficiency and improved Doyle and Green (D\&G) efficiency were conducted to provide an objective comparison and their relationship [26-30]. As for assessment variables, the weight value from the CCR model was combined with the analysis from VlseKriterijumska Optimizacija I Kompromisno Resenje (VIKOR) [27,31-33]. 
Finally, it was followed by a comparative analysis with the DEA models, and concluded the research outcomes. The research hypothesis has five folds: (1) the 12 industries chosen in the study have relatively effective modelling effect to provide reference and learning points; (2) each industry is bound to have certain industrial efficiency advantages and expected to have scalable future development; (3) there must be a certain degree of highly relevant causality between the input and output parameters during the evaluation of each model in the DEA method; (4) whether the analysis among various industries in the DEA method are homogenous, it is expected to have different results; (5) the VIKOR research method has a certain correlation with the results of the DEA method.

The hypotheses in this study were confirmed: (1) the criteria weight of performance appraisal can be determined by our designed modeling automatically to achieve optimal effect; (2) the inputs and outputs identified in this study are proven to have causal relation; and (3) the ranking analysis of the 12 chosen manufacturing industries are supported significantly.

Section 2 introduces the Taiwanese manufacturing industry landscape to understand its major indicators and development trends of 12 industries in Taiwan in detail. Section 3 explains the research methodology using DEA and VIKOR, following a serial of processes and several modelling forms. Section 4 demonstrates the research findings and discussion and includes research limitation and further research. The final section concludes this paper.

\section{Taiwanese Manufacturing Industry Landscape}

\subsection{Major Indicators in Taiwan Manufacturing}

According to the statistics of the Taiwan Institute of Economic Research in 2016, as shown in Figure 1 [34], from 2011 to 2015, the manufacturing demand, raw material input, cost, sale price, and business environment are five dominating indicators. There is a significant increase in cost, whereas other indicators are relatively lower. The scores of these four low-level indicators are even lower than five years ago. The data clearly show that the cost of manufacturing is increasing, and it is also impacted by other indicators or unknown factors. These unknowns may affect each other. Thus, it is worth to explore further to avoid the overall economic downturn. It shows a need to guide the effective strategies and policy directions, which can quickly improve the environmental system of the entire country, the structure of the industry itself, and enhance the overall competitiveness.

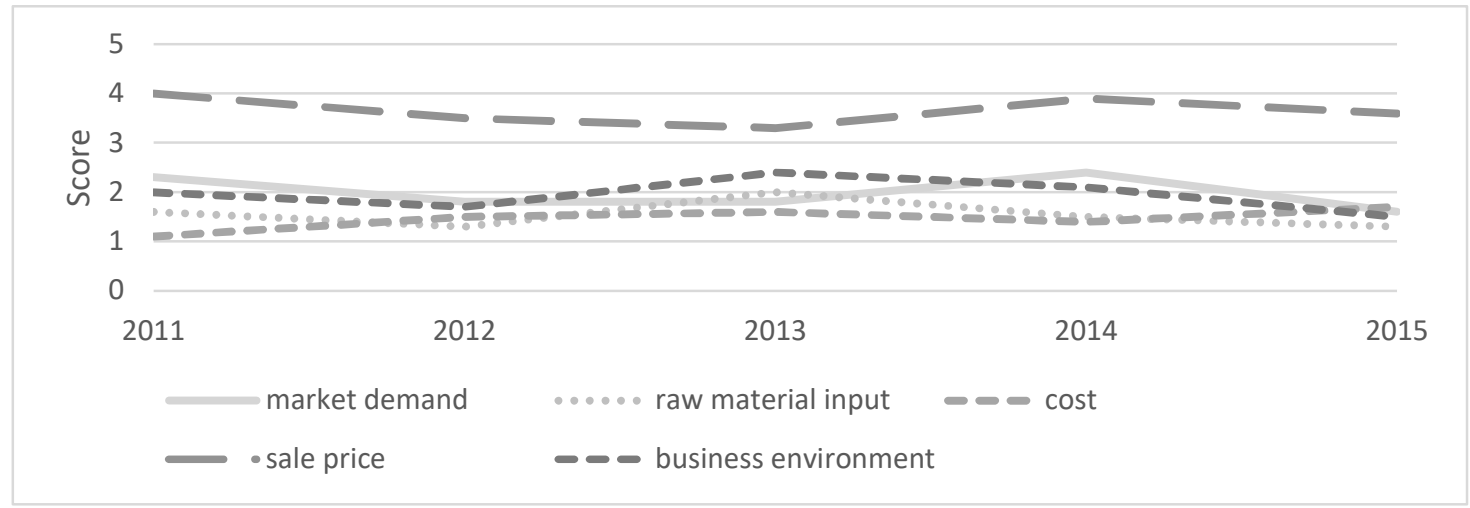

Figure 1. Five Major Indexes of Taiwan manufacturing [34].

The growth rate of the import and export of Taiwan's manufacturing industry from 2011 to 2015 is shown in Figure 2 [34]. The overall global recession in 2015 impacted Taiwan's manufacturing industry, which stopped growth and led to a substantial negative growth. Currently, it is not only due to external challenges, but also internal business operation has experienced great difficulty to survive, excel, and remain competitive in the global market. 


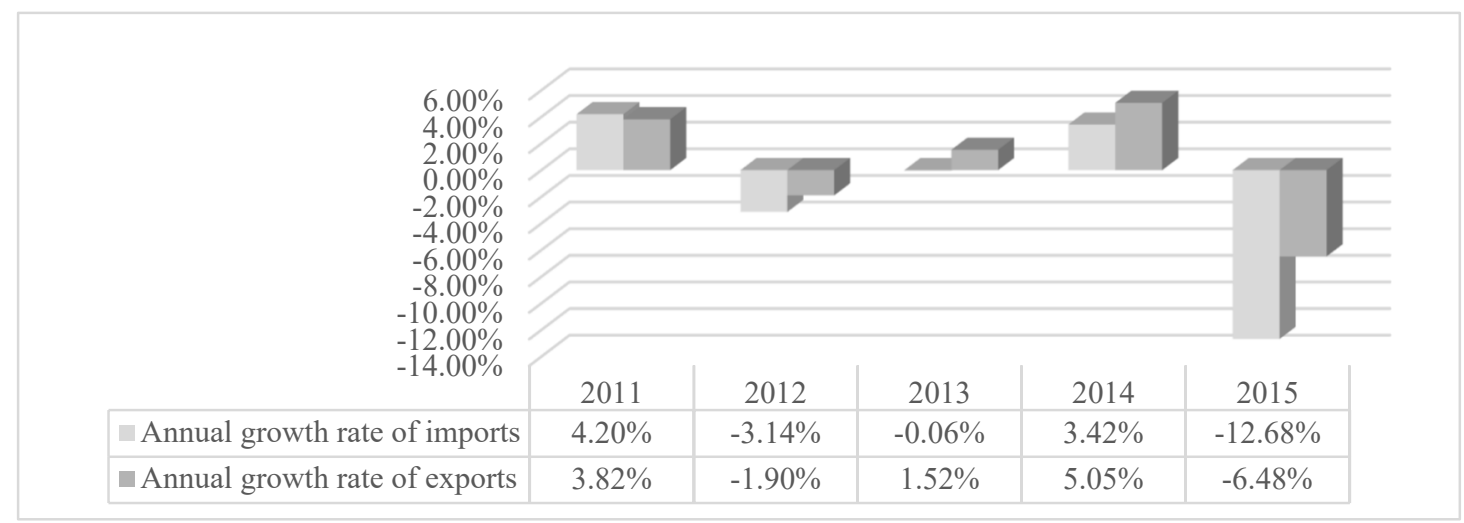

Figure 2. Annual growth rate of imports and exports in Taiwan manufacturing [34].

The Taiwan government constantly advocates industrial innovation; it encourages manufacturers to improve their business, refine their own technologies, and enhance the efficiency of production. A series of policies is facilitating the collaboration and technology exhibitions to demonstrate that Taiwan is keen to innovate in line with the world trend. It hopes to become an important factor guiding the future development in manufacturing to play a leading role in the international market.

\subsection{Development Trends of 12 Industries in Taiwan}

With the 5-year cycle data published by ITRI (Industrial Technology Research Institute), this research explores the industries that are identified in Taiwan with high potential to innovate and upgrade. At present, the Taiwan manufacturing industry has been underperforming, influenced by international competition. This section uses growth rate to overview the growth rate of the 12 Taiwan manufacturing industries.

According to the data shown in Table 1, the tire and industrial rubber manufacturing does not perform well except in 2011. In 2014, the annual performance across industries presented well. In 2015, the entire footwear manufacturing industry had a more than $50 \%$ decline, whereas the auto parts and furniture manufacturing industries showed good positive performance.

Table 1. Manufacturing Industries GDP growth rate (2011-2015).

\begin{tabular}{|c|c|c|c|c|c|}
\hline Manufacturing Industry & 2011 & 2012 & 2013 & 2014 & 2015 \\
\hline Footwear & $-18.58 \%$ & $-5.86 \%$ & $-19.45 \%$ & $3.31 \%$ & $-55.11 \%$ \\
\hline Tires and Manufacture of Industrial Rubber Products & $25.20 \%$ & $-7.52 \%$ & $-4.08 \%$ & $7.31 \%$ & $-6.23 \%$ \\
\hline Furniture & $2.46 \%$ & $8.20 \%$ & $0.54 \%$ & $7.36 \%$ & $0.67 \%$ \\
\hline Bicycles and Parts & $6.79 \%$ & $9.62 \%$ & $-5.53 \%$ & $4.35 \%$ & $10.33 \%$ \\
\hline Machine Tool (Metal Cutting Types) & $26.90 \%$ & $-6.12 \%$ & $-13.20 \%$ & $9.76 \%$ & $-8.04 \%$ \\
\hline Paper and Paper Products & $1.52 \%$ & $-4.44 \%$ & $-2.15 \%$ & $2.06 \%$ & $-3.42 \%$ \\
\hline Fabricated Metal Products & $13.57 \%$ & $-4.32 \%$ & $-5.33 \%$ & $5.24 \%$ & $-8.04 \%$ \\
\hline Woven Fabrics of Man-made Fibers & $5.21 \%$ & $-7.25 \%$ & $-0.30 \%$ & $2.89 \%$ & $-1.20 \%$ \\
\hline Wood and Products of Wood and Bamboo & $6.42 \%$ & $2.74 \%$ & $2.16 \%$ & $6.80 \%$ & $-4.79 \%$ \\
\hline Plastics Products & $3.37 \%$ & $-0.50 \%$ & $-0.85 \%$ & $2.73 \%$ & $-3.43 \%$ \\
\hline Parts for Motor Vehicles & $5.44 \%$ & $1.43 \%$ & $-1.12 \%$ & $6.99 \%$ & $0.59 \%$ \\
\hline Drugs and Medicines & $-8.42 \%$ & $2.91 \%$ & $0.64 \%$ & $0.41 \%$ & $3.74 \%$ \\
\hline
\end{tabular}

Source: Extended from the Taiwan Institute of Economic Research [34].

It is obvious that the growth rate of production in some industries has not been great. Taking a close look at the yearly changes, there are signs of slowing down or stabilizing. Among them, there are also many industries that are constantly growing. In other words, how to increase efficiency in terms of internal factors (e.g., business management, strategic planning, resource control and utilization, etc.) 
and external factors (e.g., collaboration, upstream and downstream integration, etc.) are vital to turn weakness into strength [35].

\section{Methodology}

The methodology of this research uses improved MCDM (Multi-Criteria Decision-Making) to conduct the analysis. It includes the DEA (CCR efficiency, BCC efficiency, A\&P efficiency, cross-efficiency and D\&G efficiency) and VIKOR prioritization methods to evaluate the 12 manufacturing industries in Taiwan. The Spearman analysis of the VIKOR and DEA models is also conducted in the discussion section.

The theoretical basis of DEA lies in the efficiency evaluation model developed from the perspective of technical efficiency. In other words, in all evaluation samples, the efficiency values are obtained by pair comparison to analyze decision problems. Its advantages are: (1) it can handle multi-input and multi-output evaluation mode without the need for preset functions and parameter settings, which is more feasible in practice; (2) the calculation of the efficiency value is not affected by the input and output units. This article aims to evaluate the manufacturing industry's performance by multiple inputs and outputs. If the variable value can be provided correctly, the accuracy and credibility of the DEA analysis is high. It is hoped to use DEA to compute the valid comparative efficiency in the whole industry through a more objective modelling. Besides, the efficiency model of each DEA situation is compared to find the model industry to be used as a reference for invalid industries. It is also possible to find out the reasons for the inefficiency of the invalid industry and provide directions for improvement. To enhance the accuracy, the VIKOR method is also deployed in addition to DEA. VIKOR can use the concept of compromise to deal with the competition between evaluation criteria in MCDM. This is a weight ranking method. It first defines positive and negative ideal solutions. The positive ideal solutions refer to the best alternatives in the evaluation criteria, whereas the negative ideal solutions refer to the worst. The relative weights can be found in an objective DEA-CCR model. The results thus can be applied in VIKOR calculation to find out the performance rankings of various industries. Finally, the results from VIKOR are compared with the DEA efficiency model to make the research results and analysis more complete and enhance the broader applicability and value. Therefore, the research processes are established as the Figure 3 below.

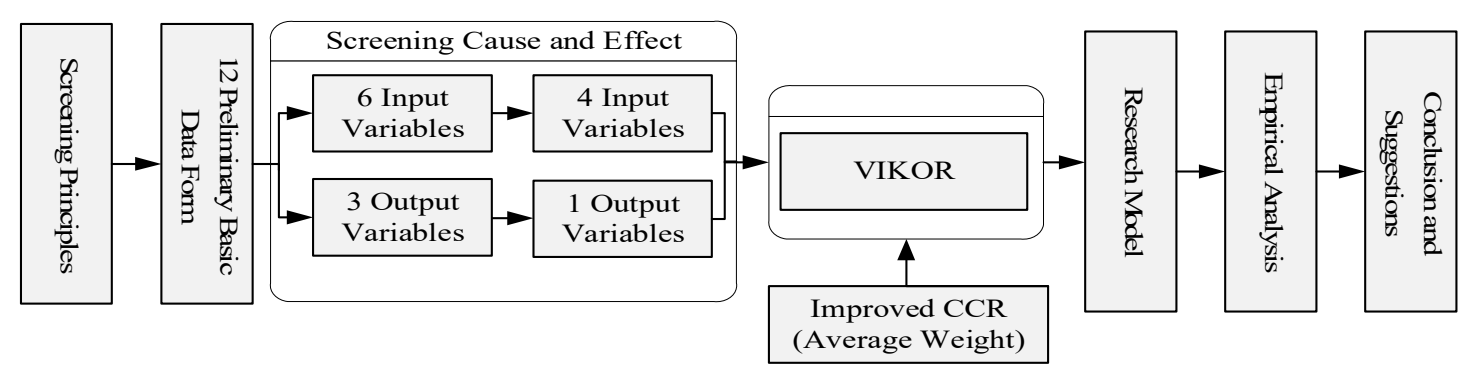

Figure 3. Research Processes. Note: 1. VIKOR (Serbian: VlseKriterijumska Optimizacija I Kompromisno Resenje, means: Multi-criteria Optimization and Compromise Solution). 2. CCR (Charnes, Cooper, \& Rhodes).

\subsection{Data Envelopment Analysis (DEA)}

The most basic DEA model is the CCR model initially proposed by Charnes, Cooper, and Rhodes in 1978, which was built on the earlier work of Farrell [36-38]. Linear programming is used to solve CCR efficiency with multiple inputs and outputs [39-42]. Following the CCR model, researchers develop several other models to provide more information about operation efficiency. This paper determines managerial efficiency using the CCR and BCC models to calculate efficiency indexes. CCR is adopted to evaluate performances of Decision-Making Units (DMUs) under the assumption of constant returns to scale. BCC is used to understand variable returns to scale, including constant, 
decreasing, and increasing $[43,44]$. The methodology has become widely acknowledged in recent years, particularly in the field of operations research and economics research [45-49]. The cross-efficiency model and A\&P model are explained as in the following subsections.

\section{Cross-Efficiency Model}

Doyle and Green [26] published a paper regarding the concept of cross-efficiency which is a kind of peer appraisal. The concept of cross-efficiency is developed in a number of new directions. The analysis grounds an intuitive understanding of cross-efficiency in the concept of peer appraisal, relative to self-appraisal implied by simple efficiency, and discusses the relative merits of each. It also presents mathematical formulations of, and intuitive meanings for, three possible implementations of aggressive and benevolent cross-efficiency. Two of these formulations have been implemented in computer programs. The performance is compared empirically on a real data set. Finally, the analysis suggests practical uses for cross-efficiency, illustrated with reference to the same data set by Doyle and Green [26]. In the CCR model, if a DMU is evaluated as efficient in self-appraisal and appears less frequently in the reference sets (more easily detected as an outlier), its cross-efficiency in peer appraisal would be decreased larger. In a cross-efficiency matrix (Table 2), ek, the cross-efficiency value of the $k$ th DMU, is an arithmetic mean of a set of virtual multipliers from the other DMUs. The formulation is as in Equation (1).

$$
e_{k}=\frac{\sum_{j \neq k} E_{j k}}{n-1}, j=1, \ldots, n, k=1, \ldots, n
$$

Table 2. Cross-efficiency matrix.

\begin{tabular}{ccccc}
\hline DMU of Peer Appraisal/DMU & $\mathbf{1}$ & $\mathbf{2}$ & $\ldots$ & $\mathbf{n}$ \\
\hline 1 & $E_{11}$ & $E_{12}$ & & $E_{1 \mathrm{n}}$ \\
2 & $E_{21}$ & $E_{22}$ & & $E_{2 n}$ \\
$n$ & $E_{n 1}$ & $E_{n 2}$ & & $E_{n n}$ \\
The cross-efficiency value of peer appraisal & $\mathrm{e}_{1}$ & $\mathrm{e}_{2}$ & $\ldots$ & $\mathrm{e}_{\mathrm{n}}$ \\
\hline Source: [26] & & & &
\end{tabular}

\section{DEA-AEP Model}

The concept of super-efficiency was first proposed by Andersen and Petersen [43] in order to improve the discrimination between efficient units in DEA. In their approach, the DMU under evaluation is assessed relative to the rest of the DMUs itself being excluded from the comparator units $[43,50]$. In super-efficiency evaluation, the DEA efficient DMUs may obtain efficiency scores that are larger than 1, which would further discriminate the DEA efficient DMUs [51]. The method promotes an alteration in the formulation of the DEA BCC model, allowing efficient DMUs to have efficiency indexes over one. In this way, it could enable to rank the most efficient DMUs [37].

\subsection{Defining Assessment Variables}

In partnership with a prestigious industrial research institute, this research was able to collect very scarce and confidential data to be employed for evaluation analysis. The data collection time period from this industrial research institute was a 5-year cycle. Thus, the data regarding the development trend from 2011 to 2015 were secured. After collecting data from public information and confirming with research institutions [34,52], several discussions with academics and ITRI experts, the entire industry performance evaluation selected evaluation variables carefully. It was based on if data sources are reliable, input and output are representative, and meeting DEA's overall variables conditional restrictions. Thus, the six input variables include the number of business departments, the number of employees, the number of R\&D factories, R\&D funds, technology procurement budget, and fixed asset 
investment. Three output variables include total income, productivity, and technical sales. Pearson correlation analysis is also calculated to eliminate noise indicators to avoid bias.

\subsection{VIKOR Method}

VIKOR (Serbian: VlseKriterijumska Optimizacija I Kompromisno Resenje, means: Multi-criteria Optimization and Compromise Solution) is provided by Opricovic [53]. The VIKOR method is one of the compromise programming methods of Multi-Criteria Decision-Making (MCDM) [54].

VIKOR assumes that each alternative is evaluated according to each criterion function. The compromise ranking is performed by comparing the measure of closeness to the ideal alternative [31,45,54]. Based on the concept of VIKOR, the positive-ideal solution and negative-ideal solution can be determined. The positive-ideal solution is the best performance value of all criterion functions among evaluated alternatives. The negative-ideal solution means the worst performance value of all criterion functions among evaluated alternatives. A firm's performance which is closest to the positive-ideal solutions and farthest from the negative-ideal solutions would be regarded as the firm with the best performance. Therefore, the total distance to positive-ideal solutions and negative-ideal solutions can be used to rank operation performances of all evaluated firms $[7,36]$.

The VIKOR method has the following steps:

(1) Normalize the evaluation values: The calculation is shown as Equation (2).

$$
f_{i j}=X_{i j} / \sqrt{\sum_{i=1}^{m} X_{i j^{\prime}}^{2}}, i=1,2, \ldots \ldots, m ; j=1,2, \ldots \ldots, n
$$

where $X_{i j}$ is the evaluation value of the $j$ th criterion of the $i$ th alternative.

(2) Determine the positive-ideal solution and negative-ideal solution: In this step, the best $f_{j}^{*}$ and the worst $f_{j}^{-}$values of all criterion functions are determined by Equation (3) and Equation (4).

$$
\begin{aligned}
& f_{j}^{*}=\operatorname{Max}_{i} f_{i j}, i=1,2, \ldots \ldots, m \\
& f_{j}^{-}=\operatorname{Minf}_{i} f_{i j}, i=1,2, \ldots \ldots, m
\end{aligned}
$$

where $f_{j}^{*}$ is the positive-ideal solution of the $j$ th criterion; $f_{j}^{-}$is the negative-ideal solution of the $j$ th criterion.

(3) Calculate the distances to the positive-ideal solutions $\left(S_{i}\right)$ and negative-ideal solutions $\left(R_{i}\right)$ and the comprehensive index $\left(I_{i}\right)$ : The distances to the positive-ideal solutions $\left(S_{i}\right)$ and negative-ideal solutions $\left(R_{i}\right)$ are calculated by Equation (5) and Equation (6).

$$
\begin{gathered}
S_{i}=\sum_{j}^{n} w_{j}\left(f_{j}^{*}-f_{i j}\right) /\left(f_{j}^{*}-f_{j}^{-}\right) \\
R_{i}=\operatorname{Max}_{j}\left[w_{j}\left(f_{j}^{*}-f_{i j}\right) /\left(f_{j}^{*}-f_{j}^{-}\right)\right]
\end{gathered}
$$

where $S_{i}$ represents the ratio of distances to the positive-ideal solutions of the $i$ th alternative (the $i$ th evaluated manufacturer); $R_{i}$ represents the ratio of distances to the negative-ideal solutions of the $i$ th alternative (the $i$ th evaluated manufacturer); $w_{j}$ is the relative weights of the $j$ th criterion obtained by the improved DEA.

Then, the comprehensive index is computed by Equation (7).

$$
I_{i}=v\left[\frac{S_{i}-S^{*}}{S^{-}-S^{*}}\right]+(1-v)\left[\frac{R_{i}-R^{*}}{R^{-}-R^{*}}\right]
$$


where $S^{*}=\min _{i} S_{i}, S^{-}=\max _{i} S_{i}, R^{*}=\min _{i} R_{i}, R^{-}=\max _{i} R_{i} ; v$ is a weight parameter. The ratio of distance from an evaluated firm to the positive-ideal solution, $\left[\left(S_{i}-S^{*}\right) /\left(S^{-}-S^{*}\right)\right]$, indicates the ratio of "group utility of the majority" of the $i$ th alternative (Majority rule); the ratio of distance from an evaluated firm to the negative-ideal solution, $\left[\left(R_{i}-R^{*}\right) /\left(R^{-}-R^{*}\right)\right]$, indicates the ratio of "individual regret of the opponent" of the $i$ th alternative; thus, the larger the value of $v(>0.5)$, the more the index $I_{i}$ trends to "group utility of the majority"(majority rule); otherwise, the smaller the value of $v(<0.5)$, the more the index $I_{i}$ trends to "individual regret of the opponent." Therefore, decision-makers can adjust the $v$ parameter as required, usually $v=0.5$.

(4) Rank the alternatives: All evaluated firms are sorting by the values of $\mathrm{Si}$, Ri, and Ii.

Thus, the VIKOR model and ranking is established as seen in Tables 3 and 4.

Table 3. Analysis Model of Relative Operation Performance by VIKOR.

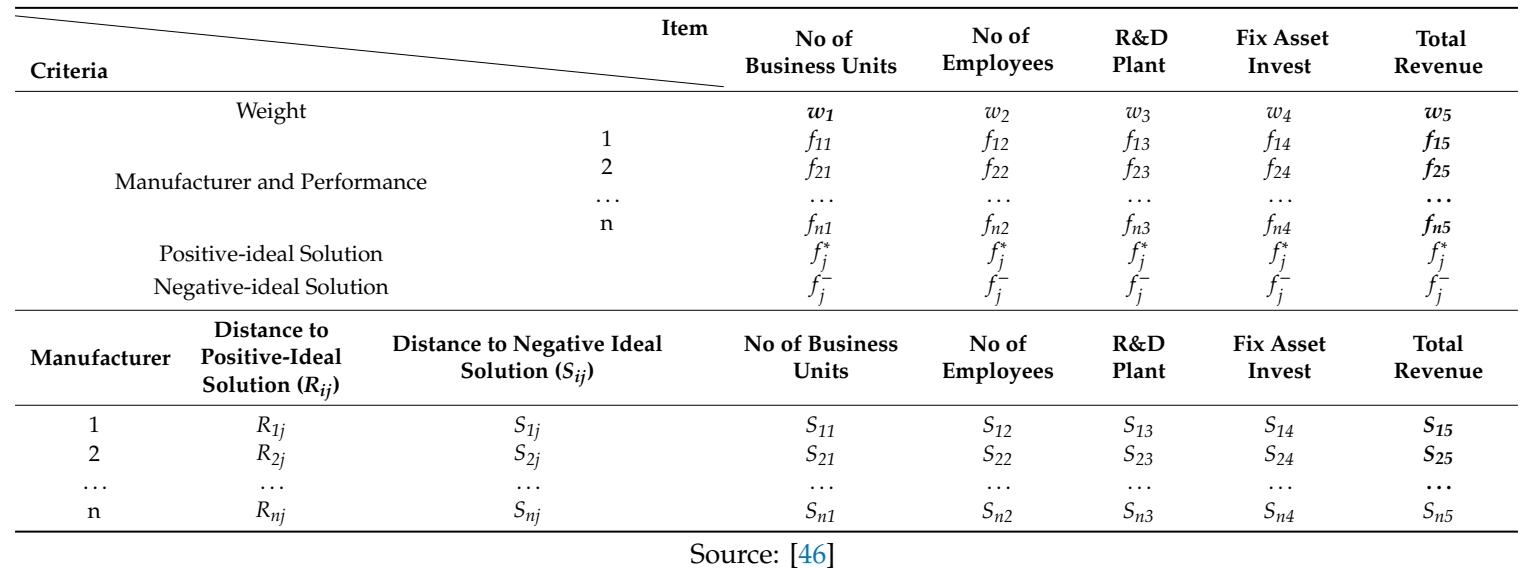

Table 4. Ranking of Evaluated Manufacturers by Comprehensive Index.

\begin{tabular}{cccccc}
\hline Manufacturers/Performance/v-Value & $\mathbf{0 . 1}$ & $\mathbf{0 . 2}$ & $\mathbf{0 . 3}$ & $\mathbf{0 . 4}$ & $\mathbf{0 . 5}$ \\
\hline 1 & $\mathrm{I}_{1}$ & $\mathrm{I}_{1}$ & $\mathrm{I}_{1}$ & $\mathrm{I}_{1}$ & $\mathrm{I}_{1}$ \\
2 & $\mathrm{I}_{2}$ & $\mathrm{I}_{2}$ & $\mathrm{I}_{2}$ & $\mathrm{I}_{2}$ & $\mathrm{I}_{2}$ \\
$\ldots$ & $\ldots$ & $\ldots$ & $\ldots$ & $\ldots$ & $\ldots$ \\
$\mathrm{n}$ & $\mathrm{I}_{\mathrm{n}}$ & $\mathrm{I}_{\mathrm{n}}$ & $\mathrm{I}_{\mathrm{n}}$ & $\mathrm{I}_{\mathrm{n}}$ & $\mathrm{I}_{\mathrm{n}}$ \\
\hline
\end{tabular}

Source: [46]

\section{Results and Discussion}

This section presents the analysis results in six subsections, including individual analysis and comparisons. The discussion is provided in Section 4.7, and the limitation and future research is also included in Section 4.8.

\subsection{Data Processing}

In the case of Pareto Optimality, if the total numbers of input and output are more than the number of DMUs in the decision-making unit, there may be problems in the degree of freedom. It may increase multiple effective DMUs and even make the efficiency value of each DMU reach the effective degree of 1 . This result is violating the origin aim of this study to target DMU relative efficiency. It is more appropriate to have at least two or more processing times to select the total number of output and input variables $[44,55]$.

In the beginning, there are 6 inputs and 3 outputs as chosen variables. There is a need to screen the right variables more precisely. Considering the nature of each variable and potential positive correlation, and at the same time excluding extreme values and those with negative direction in the 
project, the overall variables must be screened. This study used Pearson correlation analysis to calculate and obtain results. The relationship between the variables is shown in Table 5.

Table 5. Pearson Correlation Analysis Table.

\begin{tabular}{|c|c|c|c|c|}
\hline \multirow{2}{*}{ Input } & \multirow{2}{*}{ Correlation } & \multicolumn{3}{|c|}{ Output } \\
\hline & & Total Revenue & Productivity & Technical Sales Amount \\
\hline \multirow{3}{*}{ No of business units } & Coefficient & $0.929 * *$ & -0.082 & -0.169 \\
\hline & Significance & 0 & 0.801 & 0.599 \\
\hline & Number & 12 & 12 & 12 \\
\hline \multirow{3}{*}{ No of employees } & Coefficient & $0.974^{* *}$ & 0.026 & -0.176 \\
\hline & Significance & 0 & 0.936 & 0.585 \\
\hline & Number & 12 & 12 & 12 \\
\hline \multirow{3}{*}{ R\&D plants } & Coefficient & $0.889 * *$ & 0.028 & -0.178 \\
\hline & Significance & 0 & 0.931 & 0.579 \\
\hline & Number & 12 & 12 & 12 \\
\hline \multirow{3}{*}{ R\&D funds } & Coefficient & 0.549 & 0.051 & -0.024 \\
\hline & Significance & 0.064 & 0.875 & 0.94 \\
\hline & Number & 12 & 12 & 12 \\
\hline \multirow{3}{*}{ Technical purchase budget } & Coefficient & 0.495 & 0.063 & 0.17 \\
\hline & Significance & 0.102 & 0.847 & 0.597 \\
\hline & Number & 12 & 12 & 12 \\
\hline \multirow{3}{*}{ Fix Asset Invest } & Coefficient & $0.960 * *$ & 0.102 & -0.284 \\
\hline & Significance & 0 & 0.753 & 0.372 \\
\hline & Number & 12 & 12 & 12 \\
\hline
\end{tabular}

In the Pearson correlation analysis, the output variables of the Productivity and Technical sales amount are not significantly relevant. Thus, they are removed from outputs. Only the output of Total revenue remains. In terms of input, $R \& D$ funds and Technical purchase budget are not very relevant to the Total revenue. Thus, these two inputs are removed. After the screening, a set of 4 inputs and 1 output are selected for analysis. It includes 4 inputs (Number of business units, Number of employees, Number of R\&D fund, and Fixed asset investment) and 1 output, which is Total revenue (see Table 6). It ensures that the choice of DMUs in each assessment meets the homogeneity nature. Golany and Roll [56] suggested that DMUs have to be different to be able to perform various analyses and performance comparisons of relevant production performance under the same conditions $[56,57]$.

Table 6. Final Inputs and Outputs of 12 Industries.

\begin{tabular}{|c|c|c|c|c|c|}
\hline \multirow{2}{*}{ Industry (DMU) } & \multicolumn{4}{|c|}{ Input } & \multirow{2}{*}{$\begin{array}{c}\text { Output } \\
\text { Total Revenue (\$) }\end{array}$} \\
\hline & No of Business Units & No of Employees & R\&D Plants & Fix Asset Invest (\$) & \\
\hline Manufacture of Footwear & 486 & 13,295 & 22 & $16,182,000$ & $1,223,678,833$ \\
\hline $\begin{array}{l}\text { Manufacture of Tires and Manufacture of } \\
\text { Industrial Rubber Products }\end{array}$ & 412 & 19,194 & 50 & $228,097,933$ & $2,345,783,067$ \\
\hline Manufacture of Furniture & 531 & 9533 & 18 & $24,263,367$ & $940,315,900$ \\
\hline Manufacture of Bicycles and Parts & 816 & 24,687 & 66 & $145,864,767$ & $5,182,813,600$ \\
\hline $\begin{array}{c}\text { Manufacture of Machine Tool (Metal } \\
\text { Cutting Types) }\end{array}$ & 5664 & 105,329 & 332 & $651,436,067$ & $13,004,220,000$ \\
\hline Manufacture of Paper and Paper Products & 526 & 14,031 & 12 & $116,679,567$ & $2,463,959,233$ \\
\hline Manufacture of Fabricated Metal Products & 6754 & 106,193 & 150 & $608,700,433$ & $12,102,896,400$ \\
\hline $\begin{array}{c}\text { Manufacture of Woven Fabrics of } \\
\text { Man-made Fibers }\end{array}$ & 1243 & 33,922 & 60 & $185,902,867$ & $5,077,752,133$ \\
\hline $\begin{array}{c}\text { Manufacture of Wood and of Products of } \\
\text { Wood and Bamboo }\end{array}$ & 475 & 4110 & 5 & $29,170,000$ & $352,995,067$ \\
\hline Manufacture of Plastics Products & 2408 & 40,273 & 66 & $168,155,467$ & $4,059,293,800$ \\
\hline Manufacture of Parts for Motor Vehicles & 739 & 24,687 & 57 & $228,005,100$ & $4,878,503,133$ \\
\hline Manufacture of Drugs and Medicines & 108 & 6237 & 41 & $99,313,800$ & $457,642,867$ \\
\hline
\end{tabular}




\subsection{CCR Efficiency Model Analysis}

In DEA research, Charnes et al. proposed the CCR efficiency model. This is comparatively more self-centered and subjective [58]. The analysis is mainly used to judge whether the efficiency values of all DMUs reach the effective value 1 in all the DMUs. If the relative efficiency values are less than 1 , this means it is invalid.

As for the efficiency calculation results of DEA as shown in Table 5, four industries present high efficiency. The "wood and bamboo products manufacturing industry" and "metal cutting machine tool manufacturing industry" have the lowest efficiency value. However, the CCR model is more subjective self-assessment and considers the corresponding DMU reference dual value calculation. Each of the DMU reference cases listed as other DMU efficiency decisions are included in the measurement.

If the number of references is high, the relative importance of the DMU is very high. According to Table 7, the most efficient industries in the CCR modes have a considerable number of times of reference, including "bike and parts manufacturing industry," followed by "shoe manufacturing" and "paper and paper products manufacturing." As for the CCR invalid industry, none of the industry is identified. It can be observed that these effective industries not only have CCR relative efficiency standards, but also have a high importance in terms of correlation.

Table 7. DEA Values in Various Models.

\begin{tabular}{|c|c|c|c|c|c|c|c|c|c|}
\hline DMU & CCR & Reference Set & $\begin{array}{c}\text { Being } \\
\text { Referred }\end{array}$ & BCC & $\begin{array}{c}\text { BCC } \\
c \text {-Value }\end{array}$ & $\mathbf{A} \& \mathbf{P}$ & Cross & Outliner & D\&G \\
\hline $1 *$ & 1 & 1 & 6 & 1 & 0.423 & 1.951 & 0.691 & 1.824 & 0.658 \\
\hline $2 *$ & 0.862 & 11 & 0 & 0.929 & 0.313 & 0.862 & 0.509 & 0.693 & 0.382 \\
\hline $3 *$ & 0.801 & $1,4,6$ & 0 & 1 & 0.488 & 0.801 & 0.568 & 0.409 & 0.661 \\
\hline $4 *$ & 1 & 4 & 7 & 1 & 0 & 1.364 & 0.994 & 0.372 & 0.640 \\
\hline $5 *$ & 0.588 & 4 & 0 & 0.588 & 0 & 0.588 & 0.498 & 0.181 & 0.629 \\
\hline $6 *$ & 1 & 6 & 6 & 1 & 0 & 2.399 & 0.883 & 1.716 & 0.652 \\
\hline $7 *$ & 0.731 & $1,4,6$ & 0 & 0.731 & 0 & 0.731 & 0.556 & 0.313 & 0.645 \\
\hline $8 *$ & 0.900 & $1,4,6$ & 0 & 0.900 & 0 & 0.900 & 0.776 & 0.159 & 0.645 \\
\hline 9 * & 0.504 & $1,4,6$ & 0 & 1 & 1 & 0.504 & 0.369 & 0.368 & 0.665 \\
\hline 10 * & 0.721 & $1,4,6$ & 0 & 0.721 & 0 & 0.721 & 0.529 & 0.363 & 0.694 \\
\hline 11 * & 1 & 11 & 3 & 1 & 0.202 & 1.057 & 0.863 & 0.225 & 0.621 \\
\hline 12 * & 0.642 & 11 & 0 & 1 & 1 & 0.642 & 0.247 & 1.596 & 0.390 \\
\hline
\end{tabular}

$1 *$ Manufacture of Footwear; $2 *$ Manufacture of Tires and Manufacture of Industrial Rubber Products; $3 *$ Manufacture of Furniture; 4 * Manufacture of Bicycles and Parts; 5 * Manufacture of Machine Tool (Metal Cutting Types); 6 * Manufacture of Paper and Paper Products; 7 * Manufacture of Fabricated Metal Products; 8 * Manufacture of Woven Fabrics of Man-made Fibers; $9 *$ Manufacture of Wood and of Products of Wood and Bamboo; 10 * Manufacture of Plastics Products; $11 *$ Manufacture of Parts for Motor Vehicles; $12 *$ Manufacture of Drugs and Medicines.

\subsection{CCR and BCC Efficiency Model Analysis}

Continuing the CCR overall efficiency model of the DEA method in the previous section, this study analyzed all the data in the BCC mode proposed by Banker et al. It further discusses the overall inefficient DMU and figured out that the issue is in the PTE or SE. The Overall Efficiency (OE) and PTE are calculated. In other words, OE $=$ PTE $\times$ SE. The calculation results clearly show in Table 8 that the four DUM that are effective in the CCR mode are also efficient in the BCC efficiency mode. The inefficiency is affected by PTE. It means that, under the same production, the actual input of these four industries is greater than the ideal situation. It is simply due to the poor production efficiency caused by the input quantity and/or quality being inefficient. The main cause comes from the output. If the size of the investment ratio is not effective, whether the input of these three industries should be increased has to refer to the calculation result of RTS to determine if it is the case of increasing returns to scale (IRTS), constant returns to scale (CRTS) or decreasing returns to scale (DRTS). As for the cause of invalid efficiency, which is the combination of PTE and SE, it only appears in tire and rubber manufacturing. Other industries show pure invalid PTE. According to different situations, 
the industry can be fully evaluated and planned, and the different invalid reasons can be referenced to make the strategy clear, so as to improve the industry performance.

Table 8. Comparison of PTE and SE among industries.

\begin{tabular}{cccc}
\hline DMU & CCR & BCC & Scale \\
\hline Manufacture of Footwear & 1 & 1 & 1 \\
Manufacture of Tires and Manufacture of Industrial Rubber Products & 0.862 & 0.929 & 0.929 \\
Manufacture of Furniture & 0.801 & 1 & 0.801 \\
Manufacture of Bicycles and Parts & 1 & 1 & 1 \\
Manufacture of Machine Tool (Metal Cutting Types) & 0.588 & 0.588 & 1 \\
Manufacture of Paper and Paper Products & 1 & 1 & 1 \\
Manufacture of Fabricated Metal Products & 0.731 & 0.731 & 1 \\
Manufacture of Woven Fabrics of Man-made Fibers & 0.900 & 0.900 & 1 \\
Manufacture of Wood and of Products of Wood and Bamboo & 0.504 & 1 & 0.504 \\
Manufacture of Plastics Products & 0.721 & 0.721 & 1 \\
Manufacture of Parts for Motor Vehicles & 1 & 1 & 1 \\
Manufacture of Drugs and Medicines & 0.642 & 1 & 0.642 \\
\hline
\end{tabular}

\subsection{RTS Analysis}

After analyzing the PTE and SE extended by CCR and BCC in the last section, the focus of this section is on the current RTS status of each industry. It means to further explore the increase in the proportion of output of each industry and check if it can be greater than production. The measurement results are shown in Table 9. It indicates that, when the scale of production is already ideal, the RTS shows constant status. The quality could be the next priority.

Table 9. RTS Analysis and Status.

\begin{tabular}{|c|c|c|c|c|c|}
\hline DMU & $\begin{array}{c}\text { CCR } \\
\text { Efficiency }\end{array}$ & $\begin{array}{c}\text { BCC } \\
\text { Efficiency }\end{array}$ & $\begin{array}{l}\text { Scale } \\
\text { Efficiency }\end{array}$ & $\begin{array}{c}\text { RTS } \\
c \text {-value }\end{array}$ & RTS \\
\hline Manufacture of Footwear & 1 & 1 & 1 & 0.423 & increasing \\
\hline Manufacture of Furniture & 0.801 & 1 & 0.801 & 0.488 & increasing \\
\hline Manufacture of Bicycles and Parts & 1 & 1 & 1 & 0 & constant \\
\hline $\begin{array}{l}\text { Manufacture of Machine Tool } \\
\text { (Metal Cutting Types) }\end{array}$ & 0.588 & 0.588 & 1 & 0 & constant \\
\hline Manufacture of Fabricated Metal Products & 0.731 & 0.731 & 1 & 0 & constant \\
\hline $\begin{array}{c}\text { Manufacture of Woven Fabrics of } \\
\text { Man-made Fibers }\end{array}$ & 0.900 & 0.900 & 1 & 0 & constant \\
\hline Manufacture of Wood and of Products of Wood and Bamboo & 0.504 & 1 & 0.504 & 1 & increasing \\
\hline Manufacture of Plastics Products & 0.721 & 0.721 & 1 & 0 & constant \\
\hline Manufacture of Parts for Motor Vehicles & 1 & 1 & 1 & 0.202 & increasing \\
\hline
\end{tabular}

$c$-value $>0$ mean IRTS, $c$-value $=0$ mean CRTS, $c$-value $<0$ mean DRTS.

The output growth rate of these industries is significantly higher than the increase of production factors. In other words, when producing, the amount of each unit invested can be obtained, and is more than one unit of product value; hence, the strategic direction that could be more appropriate to increase the input to improve the production quantity. Based on the above, this study finds that, depending on the status of all industries, if it is not fixed by RTS, it belongs to the incremental RTS state. It represents that industrial development is still in the growth stage, and there is still room for development in the future.

\subsection{AEP Analysis of Efficiency and Cross-Efficiency Mode and Judgment of Outliers}

A\&P efficiency is to remove the self-constraints among the factors. It uses the frontier efficiency generated by other DMUs to evaluate the efficiency of itself. Functionally, the valid DMUs can be improved numerically but with no impact on invalid values. It is convenient to rank valid DMUs and 
further explore the efficiency of CCR. However, it is still a subjective self-assessment compared to other DEA efficiency models. Comparatively, the simple cross-efficiency model and D\&G model are more objective peer assessment. The outliers can be seen based on the distance of each DMU from the group. When the distance is too large, the reference value of the DMU is reduced, which can be used to assess the importance of the DMU itself.

In this study, the CCR efficiency model of valid DMUs was compared, as shown in Table 7. Based on the improved $D \& G$ overall performance ranking, it can be seen that some of the CCR efficiency evaluations are invalid. In these calculation results, the effectiveness evaluation is slightly higher than the CCR's efficiency. This study discusses and further analyzes the relevance of the various model rankings in the following sections. Although the highest and lowest efficiency results of D\&G model are slightly different from those in the CCR efficiency model, it can be found that, compared with other DEA models, those that are more efficient are "paper and paper products manufacturing." The lower one is "Western Pharmaceutical Manufacturing." Thus, the efficiency of DMU's impact assessment still holds a certain degree of importance. In Table 9, although the peer evaluation results are not identical with other models, they have generally similar direction. The next section further explores the relevance of each evaluation model.

\subsection{Correlation Analysis of Various Efficiency Models}

CCR and A\&P models are slightly more self-centered evaluation, whereas cross and improved $D \& G$ models focus on higher homogeneity in objective evaluation. In order to explore the relevance of each model, this study conducted sequential Spearman correlation analysis. The results indicate that the industries ranked on different tiers are similar. The correlation is based on SPSS analysis. The correlation between the results from CCR and A\&P rankings is 0.972 . The correlation between CCR and cross-efficiency models is 0.895 . The correlation between A\&P and cross-efficiency models is 0.881 .

The above analysis is highly correlated and highly significant. However, the improved D\&G efficiency ranking is not highly correlated or significant than the other three models. The correlation coefficients are: CCR and the number of references is -0.126 , A\&P is -0.084 , and cross-efficiency is 0.063 . It shows that there is still a certain correlation between them, and the improved D\&G model does have a positive correlation with the peer evaluation model. The self-assessment model is negatively correlated. The overall assessment indicates that the DEA assessment scenario has a positive correlation with each other in addition to the improved D\&G model.

\subsection{Discussion}

In the analysis process, the study finds the acceptable stability in decision-making conditions in industries. However, it does not fully meet the acceptable advantage conditions. Three of them meet the two requirements at the same time. The results show that these industries are the best acceptable scenarios. It verifies that they indeed have relative advantage among various industries.

The Spearman analysis results show that there is no significant correlation among various models, as shown in Table 10 between the VIKOR method and the DEA models. The results also show that there is positive correlation on self-assessment in the objective evaluation, while in the peer evaluation coexists negative and positive correlation.

Table 10. Spearman Analysis of VIKOR and DEA models Rankings.

\begin{tabular}{cccccc}
\hline \multicolumn{2}{c}{ Spearman Analysis } & CCR & A\&P & Cross & D\&G \\
\hline \multirow{4}{*}{ VIKOR } & Coefficient & 0.091 & 0.189 & -0.007 & 0.273 \\
& Significance & 0.779 & 0.557 & 0.983 & 0.391 \\
& Number & 12 & 12 & 12 & 12 \\
\hline
\end{tabular}

According to the results, the VIKOR method is mostly positively correlated with DEA. It means that the high-performing industries are able to be identified in spite of various model analyses. 
The results demonstrate that Paper and Paper Products Manufacturing and Shoe Manufacturing are relatively outstanding industries as shown in Table 11, while the other two industries, Metal Cutting Machines Manufacturing and Western Pharmaceutical Manufacturing, need to be further examined to help the industry develop better.

Table 11. DEA Efficiency Ranking.

\begin{tabular}{cccccc}
\hline DMU & CCR & A\&P & Cross & D\&G & VIKOR \\
\hline Manufacture of Footwear & 2 & 2 & 5 & 4 & 4 \\
Manufacture of Tires and Manufacture of Industrial Rubber Products & 6 & 6 & 9 & 12 & 6 \\
Manufacture of Furniture & 7 & 7 & 6 & 3 & 3 \\
Manufacture of Bicycles and Parts & 1 & 3 & 1 & 8 & 9 \\
Manufacture of Machine Tool (Metal Cutting Types) & 11 & 11 & 10 & 9 & 12 \\
Manufacture of Paper and Paper Products & 3 & 1 & 2 & 5 & 2 \\
Manufacture of Fabricated Metal Products & 8 & 8 & 7 & 6 & 11 \\
Manufacture of Woven Fabrics of Man-made Fibers & 5 & 5 & 4 & 7 & 8 \\
Manufacture of Wood and of Products of Wood and Bamboo & 12 & 12 & 11 & 2 & 1 \\
Manufacture of Plastics Products & 9 & 9 & 8 & 1 & 10 \\
Manufacture of Parts for Motor Vehicles & 4 & 4 & 3 & 10 & 7 \\
Manufacture of Drugs and Medicines & 10 & 10 & 12 & 11 & 5 \\
\hline
\end{tabular}

The comparison between the evaluation indicators all included and screening has a significant positive correlation $(\mathrm{p}<0.01)$ in purely technical efficiency analysis. The rest of the CCR models and the A\&P model are positively related, but they are not significant. The performance of all included without screening produces more relative effective values but could be more confusing. The cross-pattern of peer assessment shows significant moderate positive correlation. The improved D\&G model shows an insignificant moderate positive correlation. Therefore, these two analyses do exist some extent difference. The combined analysis using the DEA and VIKOR methods has verified the 12 selected industries' performance. The input items include the number of units, employees, R\&D plants, and fixed-assets investment. The output items include revenue, R\&D expenses, and $R \& D$ income. The eliminated measuring items do not mean no impact but it depends on the timing, cycle, or maturity level.

After empirical analysis from the above researching and discussing with experts from the Industrial Technology Research Institute (ITRI), it is considered that Taiwan could make the following suggestions in the future development of these 12 industries:

1. The industry is suggested to use design innovation to move towards higher value of its own brands, such as: Footwear, Furniture, Bicycle and Parts, Paper and Paper Products, Wood and of Products of Wood and Bamboo.

2. Taiwan's industrial chain strengthens the cooperation of upstream, midstream, and downstream through digital integration, for example: Tires and Manufacture of Industrial Rubber Products, Bicycles and Parts, Machine Tool (Metal Cutting Types), Fabricated Metal Products, Woven Fabrics of Man-made Fibers, Plastics Products, Parts for Motor Vehicles, Drugs and Medicines.

3. The government assists in the introduction of AI (Artificial Intelligence) to improve the quality and competitiveness of the manufacturing industry, such as Footwear, Tires and Manufacture of Industrial Rubber Products, Furniture, Machine Tool (Metal Cutting Types), Paper and Paper Products, Fabricated Metal Products, Woven Fabrics of Man-made Fibers, Plastics Products, Parts for Motor Vehicles, Drugs and Medicines.

\subsection{Reseach Limitation and Future Research}

This research is limited by only analyzing one country, which is Taiwan, during certain time periods with limited data. While this research has produced rich analysis and implications, there could be some constraints on generalizability to apply or practice to other industry sectors in different countries. Especially, the current industry competition constantly faces unanticipated challenges that emerge 
internally and externally. It is suggested in the future research, a longitudinal study with more recent data and benchmarking analysis across various countries to investigate this research problem, and to measure change or stability over time is a good direction. In doing so, it would add more larger-scale recommendations for further scientific research and improvements in manufacturing sectors.

\section{Conclusions}

Global competition is often impacted by technology advancement, including the software and hardware upgrades. The benchmarking analysis is to understand the industry performance to improve the production capacity and decrease the inefficiency, which is critical for the manufacturing industry. Taiwan is quite a valuable case for those emerging countries interested in creating a national policy and innovation strategy for transforming themselves from low-value to high-technology embedded high-value producers. How to increase efficiency in terms of internal factors (e.g., business management, strategic planning, resource control and utilization, etc.) and external factors (e.g., collaboration, upstream and downstream integration, etc.) are vital but yet under-researched to turn weakness into strength. This research uses the cases in Taiwan to unpack the mystery of how to evaluate industry performance to maintain its advantages or enhance its competitiveness to becoming sustainable firms. Therefore, this study used DEA to analyze first and used VIKOR for further investigation. The analysis of 12 major manufacturing industries in Taiwan has shown individual competitiveness and relative potential. The original DEA-CCR and the improved A\&P models with more subjective evaluation have shown that the high-performing industry in terms of efficiency is Shoe Manufacturing and Paper and Paper Products Manufacturing. Those who are underperforming are Western Pharmaceutical Medicine Manufacturing and Metal Cutting Machine Tool Manufacturing. The contribution is that well-performing industries can be the best practice to learn from, whereas the underperforming industries are identified to strategize for improvement. According to CCR and BCC evaluation, Shoe Manufacturing, Bicycle and Parts Manufacturing, Paper and Paper Products Manufacturing, and Auto Parts Manufacturing have achieved effectiveness from the viewpoints of overall, purely technical efficiency, and scale efficiency. The ineffective industrial sector goes to Tire and Industrial Rubber Manufacturing according to pure technical efficiency and scale efficiency. The least effective industry belongs to Metal Cutting Machine Tool Manufacturing according to purely technical efficiency. The least effective industry goes to Wood and Bamboo Products Manufacturing according to scale efficiency. Overall, 4 out of 12 industries have been effective. Except for Tire and Industrial Rubber Manufacturing, the other 8 industries are simply purely technically inefficient or inefficient in scale. The factors caused by the impact of the inefficiency could be obvious to provide the direction to improve. In the RTS part, half of the manufacturing industries of all DMUs belong to the CRTS, and the other half belong to the IRTS state. The whole development represents the various industries explored in this research belonging to the stage of growth. Further investment in the future can be increased to boost in-depth development and competitive potential.

On a global scale, in order to maintain market competitiveness, the manufacturing industry has struggled with sustainable development as an important goal and initiated many sustainable strategies accordingly. The main aspects of sustainability such as economy, society, and environment are considered, whereas, at the same time, how to enhance performance becomes an important indicator. While facing the transformation of the traditional manufacturing industry to achieve sustainable business operations, Taiwan's manufacturing industry case can provide rich implications as to how to evaluate performance using different models to achieve international market competitiveness in a unique direction. It is essential for policy-makers and practitioners to understand the underlying causes and mechanisms to enhance sustainability by supportive means (such as government's procurement and financial incentives), and how to evaluate industry performance to promote industrial competitiveness and technological innovation. 
Author Contributions: Z.-Y.L., Y.-T.W. and K.-J.C. conceived and designed the study, analyzed the data, structured the article and wrote the draft. M.-T.C. reviewed and edited the manuscript. All authors have read and agreed to the published version of the manuscript.

Funding: This research received external funding.

Acknowledgments: I would like to appreciate the support from Industrial Technology Research Institute (ITRI) for the funding of this research project. It also includes reliable data supply, research material of 12 manufacturing sectors, and professional opinions.

Conflicts of Interest: The authors declare no conflict of interest.

\section{References}

1. Giffi, C.A.; Rodriguez, M.D.; Gangula, B.; Roth, A.V.; Roth, A.V. Global Manufacturing Competitiveness Index; Deloitte Touche Tohmatsu Limited (DTTL) Global Consumer \& Industrial Products Industry Group and the Council on Competitiveness: London, UK, 2016.

2. Kao, C.; Liu, S.-T. Measuring performance improvement of Taiwanese commercial banks under uncertainty. Eur. J. Oper. Res. 2014, 235, 755-764. [CrossRef]

3. Chen, S.-L.; Liang, H.-A. Cause mapping of simple and complex marketing strategies. J. Bus. Res. 2014, 67, 2867-2876. [CrossRef]

4. Sun, Y. Locational Movement of PC Manufacturing Firms in East Asia. In Locational Analysis of Firms' Activities from a Strategic Perspective; Springer: Berlin/Heidelberg, Germany, 2018; pp. 53-73.

5. Lii, P.; Kuo, F.-I. Innovation-oriented supply chain integration for combined competitiveness and firm performance. Int. J. Prod. Econ. 2016, 174, 142-155. [CrossRef]

6. Hsueh, C.-C.; Chen, D.-Z. A taxonomy of patent strategies in Taiwan's small and medium innovative enterprises. Technol. Forecast. Soc. Chang. 2015, 92, 84-98. [CrossRef]

7. Chen, C.T.; Pai, P.F.; Hung, W.Z. Applying linguistic VIKOR and knowledge map in personnel selection. Asia Pac. Manag. Rev. 2011, 16, 491-502. [CrossRef]

8. Chen, Y.-M.; Su, Y.-F.; Lin, F.-J. Country-of-origin effects and antecedents of industrial brand equity. J. Bus. Res. 2011, 64, 1234-1238. [CrossRef]

9. Chen, Y.-M. The continuing debate on firm performance: A multilevel approach to the IT sectors of Taiwan and South Korea. J. Bus. Res. 2010, 63, 471-478. [CrossRef]

10. Kao, Y.S.; Nawata, K.; Huang, C.Y. Systemic functions evaluation based technological innovation system for the sustainability of IoT in the manufacturing industry. Sustainability 2019, 11, 2342. [CrossRef]

11. Johnson, J.H.; Arya, B.; Mirchandani, D.A. Global integration strategies of small and medium multinationals: Evidence from Taiwan. J. World Bus. 2013, 48, 47-57. [CrossRef]

12. Wu, D.D.; Zhang, Y.; Wu, D.; Olson, D.L. Fuzzy multi-objective programming for supplier selection and risk modeling: A possibility approach. Eur. J. Oper. Res. 2010, 200, 774-787. [CrossRef]

13. Lin, W.-T. FDI decisions and business-group insider control: Evidence from Taiwanese group-affiliated firms investing in the Chinese market. J. World Bus. 2016, 51, 525-533. [CrossRef]

14. Hung, S.-W.; Lu, W.-M.; Wang, T.-P. Benchmarking the operating efficiency of Asia container ports. Eur. J. Oper. Res. 2010, 203, 706-713. [CrossRef]

15. Wiboonchutikula, P.; Phucharoen, C.; Pruektanakul, N. Spillover Effects of Foreign Direct Investment on Domestic Manufacturing Firms in Thailand. Singap. Econ. Rev. 2016, 61, 1640028. [CrossRef]

16. Emodi, N.V.; Murthy, G.P.; Emodi, C.C.; Emodi, A.S.A. Factors Influencing Innovation and Industrial Performance in Chinese Manufacturing Industry. Int. J. Innov. Technol. Manag. 2017, 14, 1750040. [CrossRef]

17. Development, C.F.E.P.A.; Executive Yuan, R.O.C.T. Economic Development, R.O.C. (Taiwan) 2016. Available online: https://www.ndc.gov.tw/en/ (accessed on 3 May 2016).

18. Tzeng, Z.-C. The Big Dilemma of Taiwan's Industrial Development Is the Rise of Industrial Enterprises Outside the Industry 2017, National Policy Foundation. Available online: https://www.npf.org.tw/3/17548 (accessed on 20 October 2017).

19. Drobyazko, S.; Okulich-Kazarin, V.; Rogovyi, A.; Marova, S. Factors of influence on the sustainable development in the strategy management of corporations. Acad. Strateg. Manag. J. 2019, 18, 1-5.

20. Chang, A.Y.; Cheng, Y.T. Analysis model of the sustainability development of manufacturing small and medium-sized enterprises in Taiwan. J. Clean. Prod. 2019, 207, 458-473. [CrossRef] 
21. Yang, J.; Chen, M.L.; Fu, C.Y.; Chen, X.D. Environmental policy, tax, and the target of sustainable development. Environ. Sci. Pollut. Res. 2019, 2019, 1-10. [CrossRef]

22. Feng, D.; Chen, Q.; Song, M.; Cui, L. Relationship between the degree of internationalization and performance in manufacturing enterprises of the Yangtze river delta region. Emerg. Mark. Financ. Trade 2019, 55, 1455-1471. [CrossRef]

23. Li, G.; Shi, X.; Yang, Y.; Lee, P.K. Green Co-Creation Strategies among Supply Chain Partners: A Value Co-Creation Perspective. Sustainability 2020, 12, 4305. [CrossRef]

24. Singh, L. Competitiveness, skill formation and industrialization: The South Asian experience. In Manufacturing and Jobs in South Asia; Springer: Singapore, 2019; pp. 213-227.

25. Lee, Z.Y.; Chu, M.T.; Chen, S.S.; Tsai, C.H. Identifying Comprehensive Key Criteria of Sustainable Development for Traditional Manufacturing in Taiwan. Sustainability 2018, 10, 3275. [CrossRef]

26. Doyle, J.; Green, R. Efficiency and Cross-Efficiency in DEA: Derivations, Meanings and Uses. J. Oper. Res. Soc. 1994, 45, 567-578. [CrossRef]

27. Peng, M.; Song, L.; Guohui, L.; Sen, L.; Heping, Z. Evaluation of Fire Protection Performance of Eight Countries Based on Fire Statistics: An Application of Data Envelopment Analysis. Fire Technol. 2012, 50, 349-361. [CrossRef]

28. Ruggiero, J. Measuring the Cost of Meeting Minimum Educational Standards: An Application of Data Envelopment Analysis. Educ. Econ. 2007, 15, 1-13. [CrossRef]

29. Sexton, T.R.; Silkman, R.H.; Hogan, A.J. Data envelopment analysis: Critique and extensions. New Dir. Program Eval. 1986, 32, 73-105. [CrossRef]

30. Sun, L.; Rong, J.; Yao, L. Measuring Transfer Efficiency of Urban Public Transportation Terminals by Data Envelopment Analysis. J. Urban Plan. Dev. 2010, 136, 314-319. [CrossRef]

31. Opricovic, S.; Tzeng, G.-H. Compromise solution by MCDM methods: A comparative analysis of VIKOR and TOPSIS. Eur. J. Oper. Res. 2004, 156, 445-455. [CrossRef]

32. Wang, S.C.; Chen, M.K. The use of a hybrid ANP-VIKOR approach for establishing the performance evaluation model of e-business project. Afr. J. Bus. Manag. 2014, 8, 242-252. [CrossRef]

33. Nisel, S. An Extended VIKOR Method for Ranking Online Graduate Business Programs. Int. J. Inf. Educ. Technol. 2014, 4, 103-107. [CrossRef]

34. Department of Statistics, M.O.E.A. Industrial Production Statistics 2016. Available online: https://www.moea. gov.tw/MNS/dos_e/home/Home.aspx (accessed on 31 January 2016).

35. Le Nguyen, H.; Larimo, J.; Wang, Y. Control, innovation and international joint venture performance: The moderating role of internal and external environments. Int. Bus. Rev. 2019, 28, 101591. [CrossRef]

36. Büyüközkan, G.; Görener, A. Evaluation of product development partners using an integrated AHP-VIKOR model. Kybernetes 2015, 44, 220-237. [CrossRef]

37. de Carvalho Miranda, R.; Montevechi, J.A.B.; da Silva, A.F.; Marins, F.A.S. Increasing the efficiency in integer simulation optimization: Reducing the search space through data envelopment analysis and orthogonal arrays. Eur. J. Oper. Res. 2017, 262, 673-681. [CrossRef]

38. Shah, A.A.; Wu, D.; Korotkov, V. Are sustainable banks efficient and productive? A data envelopment analysis and the Malmquist productivity index analysis. Sustainability 2019, 11, 2398. [CrossRef]

39. Barnum, D.T.; Walton, S.M.; Shields, K.L.; Schumock, G.T. Measuring hospital efficiency with Data Envelopment Analysis: Nonsubstitutable vs. substitutable inputs and outputs. J. Med. Syst. 2011, 35, 1393-1401. [CrossRef] [PubMed]

40. Flokou, A.; Kontodimopoulos, N.; Niakas, D. Employing post-DEA cross-evaluation and cluster analysis in a sample of Greek NHS hospitals. J. Med. Syst. 2011, 35, 1001-1014. [CrossRef] [PubMed]

41. Sanjuan, N.; Ribal, J.; Clemente, G.; Fenollosa, M.L. Measuring and Improving Eco-efficiency Using Data Envelopment Analysis. J. Ind. Ecol. 2011, 15, 614-628. [CrossRef]

42. Schumock, G.T.; Shields, K.L.; Walton, S.M.; Barnum, D.T. Data envelopment analysis: A method for comparing hospital pharmacy productivity. Am. J. Health Syst. Pharm. 2009, 66, 1660-1665. [CrossRef] [PubMed]

43. Andersen, P.; Petersen, N.C. A Procedure for Ranking Efficient Units in Data Envelopment Analysis. Manag. Sci. 1933, 39, 1261-1264. [CrossRef]

44. Banker, R.D.; Charnes, A.; Cooper, W.W. Some Models for Estimating Technical and Scale Inefficiencies in Data Envelopment Analysis. Manag. Sci. 1984, 30, 1078-1092. [CrossRef] 
45. Kuosmanen, T.; Kortelainen, M. Measuring Eco-efficiency of Production with Data Envelopment Analysis. J. Ind. Ecol. 2005, 9, 59-72. [CrossRef]

46. Lee, Z.-Y.; Pai, C.-C. Applying Improved DEA \& VIKOR Methods to Evaluate the Operation Performance for World's Major TFT-LCD Manufacturers. Asia-Pac. J. Oper. Res. 2015, 32, 1550020. [CrossRef]

47. Nold Hughes, P.A.; Edwards, M.E. Leviathan vs. Lilliputian: A Data Envelopment Analysis of Government Efficiency. J. Reg. Sci. 2000, 40, 649-669. [CrossRef]

48. Zaim, S.; Bayyurt, N.; Turkyilmaz, A.; Solakoglu, N.; Zaim, H. Measuring and Evaluating Efficiency of Hospitals Through Total Quality Management. J. Transnatl. Manag. 2008, 12, 77-97. [CrossRef]

49. Zhou, Z.; Wu, J. Applying a Peer-Restricted Cross-Efficiency Approach to Measuring the Performance of International Tourist Hotels in Taipei. J. Hosp. Mark. Manag. 2014, 23, 157-177. [CrossRef]

50. Afsharian, M.; Ahn, H.; Thanassoulis, E. A DEA-based incentives system for centrally managed multi-unit organisations. Eur. J. Oper. Res. 2017, 259, 587-598. [CrossRef]

51. Wu, J.; Chu, J.; Sun, J.; Zhu, Q.; Liang, L. Extended secondary goal models for weights selection in DEA cross-efficiency evaluation. Comput. Ind. Eng. 2016, 93, 143-151. [CrossRef]

52. Chen, C.-J. Research and Application of Design Innovation in Central Taiwan. 2016. Retrieved from Unpublished.

53. Opricovic, S. Multicriteria optimization of civil engineering systems. Fac. Civ. Eng. Belgrade 1998, 2, 5-21.

54. Opricovic, S.; Tzeng, G.-H. Extended VIKOR method in comparison with outranking methods. Eur. J. Oper. Res. 2007, 178, 514-529. [CrossRef]

55. Ali, A.I.; Lerme, C.S.; Seiford, L.M. Components of efficiency evaluation in data envelopment analysis. Eur. J. Oper. Res. 1995, 80, 462-473. [CrossRef]

56. Golany, B.; Roll, Y. An application procedure for DEA. Omega 1989, 17, 237-250. [CrossRef]

57. Mahdiloo, M.; Noorizadeh, A.; FarzipoorSaen, R. Optimal direct mailing modelling based on data envelopment analysis. Expert Syst. 2014, 31, 101-109. [CrossRef]

58. Charnes, A.; Cooper, W.W.; Rhodes, E. Measuring the efficiency of decision making units. Eur. J. Oper. Res. 1978, 2, 429-444. [CrossRef] 